\title{
Influencing factors of mental and bone health status of older women
}

\author{
Qin $\mathrm{DAI}^{1}$, Chunjing $\mathrm{FU}^{1}$, Wei JIANG ${ }^{1}$, Lanling $\mathrm{CHEN}^{1}$, Tingting $\mathrm{WAN}^{1}$, Yanqiu $\mathrm{XU}^{1}$, Niansha $\mathrm{XU}^{1}$, Hongrong $\mathrm{GUO}^{1 *}$
}

\begin{abstract}
Objective: To investigate the influencing factors that influence the mental and bone health status of older women. Methods: A total of 576 older women aged more than 75 years old were recruited from 30 communities. Participants completed the Kessler Psychological Distress Scale (K10). Participants' bone mineral density was measured by ultrasound bone densitometer or dual energy X-ray absorptiometry. Results: The average K10 score was (14.78 \pm 4.23$)$. There were 352 subjects (61.11\%) in "good" mental health status, $158(27.43 \%)$ in general status and 66(11.46\%) in poor status. There were 315 older women(54.69\%) who developed OP, and they had significantly higher K10 score than the non-OP subjects. A Multivariate Logistic Regression analysis showed that poor mental status, aging, age at menarche $<16$ years, long time of menopause, more delivery times were the risk factors for OP in older women, while regular exercise and high BMI were the protective factors against OP in older women. Pearson Correlation Coefficient analysis showed that bone mineral density was negatively correlated with K10 score. Conclusion: Mental and bone health of older women are affected by a variety of factors. Clinical care can focus on providing comprehensive prevention and control of these factors.
\end{abstract}

Keywords: older women; Kessler Psychological Distress Scale; mental health status; bone health; osteoporosis; cross-sectional study.

Practical Application: Comprehensive means of prevention and control for these specific factors can improve the mental health status, reduce their incidence of $\mathrm{OP}$, and promote their quality of life in the older women later years.

\section{Introduction}

With the rapid economic development and changing cultural environment in China, the elders face not only physiological diseases, but also mental problems. It has been reported that $39.86 \%$ of the elders in urban communities have been bothered by depressive symptoms (Kingstone et al., 2017). With the increasing aging population, the mental health consultation rate for the elders are caused by retirement, widowhood, and living alone, and their mental health must be addressed (DarinMattsson et al., 2018).

Epidemiological studies have found that the incidence of osteoporosis (OP) is increasing in older women. OP is a major health problem in developing countries, and its prevalence is of great significance for formulating plans of taking preventive health measures and improving community health services (Spångéus et al., 2017) The prevalence of OP in women over 50 years old is $32.1 \%$, and that in women over 65 years old is rising to $51.6 \%$ in China (Gu et al., 2019. A previous study has showed that older women who have OP are more likely to suffer from mental, physiological, social and other functional disorders (Zhu et al., 2018b). The physical degradation and pain that are caused by shortened body length and rickets are more likely to cause psychological dysfunction in older women and affect their physical and mental health. Therefore, the disease symptoms and adverse mental health form a vicious cycle.

In our study, we aimed to investigate the mental and bone health status of older women and to analyze the influencing factors, with the hope to intervene and control the preventable factors of mental and bone problems as much as possible. Ultimately, we seek to improve the physical and mental health of older women, raise their awareness about OP, and provide an epidemiological basis for countermeasures against domestic public health problems.

\section{Subjects and methods}

\subsection{General information}

A total of 576 older women in 30 communities were recruited using a convenience sampling method from May 2018 to February 2020. These subjects aged more than 75 years, with the average age of $(83.2 \pm 5.6)$ years. Their body mass index (BMI) was $(23.45 \pm 3.21) \mathrm{kg} / \mathrm{m}^{2}$. their pregnancy times were (3.21 \pm 1.10$)$, and their delivery times were $(1.98 \pm 0.32)$. Their menarche age was $(14.6 \pm 2.4)$ years old and the menopausal 
time was $(28.9 \pm 3.7)$ years. A total of 600 questionnaires were distributed and 576 were collected.

Inclusion criteria: 1 ) age $\geq 75$ years; 2 ) community residence time $\geq 1$ year; 3 ) clear consciousness; 4) ability for normal communication; 5) ability for reading, hearing and verbal expression; and 6) the understanding of the investigation and consent for participation. Exclusion criteria: 1) older women with senile dementia, cognitive dysfunction or mental disorders; and 2) older women who declined to participate. The study was approved by the Ethical Committee of Wuhan Third Hospital and all subjects signed the informed consent document.

\subsection{Methods and measurement standards}

\section{General information questionnaire}

A self-designed questionnaire was used and investigations were conducted by the trained investigators. The questionnaire included age, marital status, education level, living condition, income status, ability of daily living, filial piety from children, diseases, sleep quality, exercise, subjective well-being, loneliness, age at menarche, menopausal time (years), BMI and times of pregnancy and delivery.

\section{Investigations of mental health}

The frequency of symptoms related to non-specific mental health, such as anxiety and stress levels over the past four weeks, was measured by using Kessler Mental Disorders Scale 10 (K10) table. There were 50 points at ten items. A five-point Likert scale was adopted as the scoring method to report symptom frequency, ranging from " $1=$ rarely," to " $5=$ all of the time." The scores of $10-15$ points, $16-21$ points, $22-29$ points and $30-50$ points indicate good, general, relatively poor and poor mental health status, respectively (Uddin et al., 2018).

\section{Physical examination}

Height and weight were measured and recorded by the trained physical examination personnel using HW-900Y (Henan Lejia Electronic Technology Co., Ltd.). BMI $\left(\mathrm{kg} / \mathrm{m}^{2}\right)$ was calculated after measurement.

\section{Bone mineral density (BMD) measurement}

BMD was measured by an ultrasound bone densitometer SONOST3000 (Osteosys Co., Ltd., SEOUL, South Korea). The height and weight measured previously were input and then the right foot was sterilized to measure the attenuation coefficient of ultrasonic amplitude and ultrasound conduction velocity. Digital dual energy X-ray absorptiometry (DEXA; MEDIX90, Medlink, France) was also used to measure the BMD at lumbar (L2-L4) and proximal femur. Bone mass was measured by $\mathrm{T}$ value, which was the standard deviation (SD) between the BMD value and the mean BMD value of normal young females. One $\mathrm{SD}$ was equal to $12 \%$ of the normal $\mathrm{BMD}$ value. T value $\geq-1 \mathrm{SD}$ indicates normal BMD; $-2.5 \mathrm{SD}<\mathrm{T}$ value $<-1 \mathrm{SD}$ indicates low BMD; $\mathrm{T}$ value $\leq-2.5$ SD indicates OP (Link \& Kazakia, 2020).

\subsection{Outcome measures}

Univariate analyses were conducted to analyze the influencing factors of mental health of older women. Factors showing statistical significance at a univariate level were selected as the independent variables to perform a multivariate logistic regression analysis, with K10 total scores as the dependent variable.

Univariate analyses was performed to identify the possible pathogenic factors of OP. The independent risk factors of OP were analyzed by multivariate Logistic Regression analysis. OP status (whether or not the subject had OP) was the dependent variable. The other nine factors were the independent variables, including age, age at menarche, menopausal years, BMI, times of pregnancy and delivery, exercise and mental status. Incidence of OP $(\%)=$ the number of OP subjects in an indicator / total number of subjects in an indicator ${ }^{\star} 100$.

In addition, the correlation between mental health score and BMD was analyzed by Pearson Correlation Coefficient (PCC) analysis.

\subsection{Statistical analyses}

All statistical data were analyzed and processed by SPSS21.0 software. Measurement data were expressed as mean \pm standard deviation (SD) or P50 (P25; P75). Measurement data conforming to the normal distribution were analyzed by $\mathrm{t}$ test, $\mathrm{F}$ test, or analysis of variance. Data that were not normally distributed were analyzed by non-parametric tests. Count data were expressed by number of cases / percentage $(\mathrm{n} / \%)$ and analyzed by $\chi^{2}$ test. Univariate analysis and multivariate logistic regression analysis were used to analyze the influencing factors of mental health and bone status. PCC analysis was used to analyze the mental health score and BMD of the subjects. $p<0.05$ indicated that the difference was statistically significant.

\section{Results}

\subsection{Univariate analysis of influencing factors on mental health status of older women}

The K10 scores of older woman were varied due to the differences in living condition, education level, salary, ability of daily living, filial piety from children, diseases, sleep quality, exercise, subjective well-being, sense of loneliness and OP development (all $p<0.05)$. The K10 score of OP patients $(15.78 \pm 4.22)$ was significantly higher than that of non-OP subjects $(13.65 \pm 3.16)$ $(p<0.05)$ (Table 1).

\subsection{Multivariate Logistic regression analysis of the risk factors of mental status of older women}

The multivariate logistic regression analysis showed that living alone, low education level, low salary, poor ability of daily living, dissatisfaction with filial piety from children, suffering from OP or other diseases, poor sleep quality, irregular exercise, poor subjective well-being and loneliness were all risk factors for poor mental health quality (all $p<0.05$, Table 2 ). The variable assignment was shown in Table 3. 


\section{Dai et al.}

Table 1. Single factor analysis of influencing factors of mental health status of older women.

\begin{tabular}{|c|c|c|c|c|c|}
\hline \multicolumn{2}{|c|}{ Index } & \multirow{2}{*}{$\begin{array}{c}\text { Cases } \\
265\end{array}$} & \multirow{2}{*}{$\begin{array}{l}\text { K10 score } \\
14.34 \pm 2.16\end{array}$} & \multirow[t]{2}{*}{$t / F$} & \multirow[t]{2}{*}{$\mathbf{P}$} \\
\hline Age (years) & $<80$ & & & & \\
\hline & $80-89$ & 233 & $14.82 \pm 2.53$ & 6.737 & 0.000 \\
\hline & $>90$ & 78 & $15.74 \pm 3.37$ & & \\
\hline \multirow[t]{2}{*}{ Spouse (with/without) } & Yes & 373 & $14.23 \pm 2.26$ & \multirow{2}{*}{0.687} & \multirow{2}{*}{0.493} \\
\hline & No & 203 & $14.39 \pm 2.87$ & & \\
\hline \multirow[t]{3}{*}{ Education level } & Literate & 179 & $15.34 \pm 3.61$ & \multirow{3}{*}{7.334} & \multirow{3}{*}{0.000} \\
\hline & Junior high school or below & 229 & $14.21 \pm 3.45$ & & \\
\hline & High school or above & 168 & $13.76 \pm 2.38$ & & \\
\hline \multirow[t]{2}{*}{ Living alone } & Yes & 178 & $17.23 \pm 4.42$ & \multirow{2}{*}{8.365} & \multirow{2}{*}{0.000} \\
\hline & No & 398 & $14.23 \pm 2.74$ & & \\
\hline \multirow[t]{4}{*}{ Salary (RMB) } & $<1,000$ & 30 & $17.92 \pm 4.45$ & \multirow{4}{*}{5.332} & \multirow{4}{*}{0.000} \\
\hline & $1,000-2,000$ & 148 & $15.64 \pm 3.32$ & & \\
\hline & $2,000-3,000$ & 278 & $13.19 \pm 3.05$ & & \\
\hline & $>3,000$ & 120 & $12.07 \pm 2.01$ & & \\
\hline \multirow{3}{*}{ Ability of daily living } & No Problem & 405 & $12.56 \pm 2.34$ & \multirow{3}{*}{5.345} & \multirow{3}{*}{0.000} \\
\hline & Having some problem & 122 & $14.32 \pm 2.73$ & & \\
\hline & Unable to participant in daily activities & 49 & $16.78 \pm 4.29$ & & \\
\hline \multirow[t]{2}{*}{ Filial piety } & Satisfied & 339 & $12.32 \pm 1.92$ & \multirow{2}{*}{16.385} & \multirow{2}{*}{0.000} \\
\hline & Not satisfied & 237 & $16.37 \pm 3.45$ & & \\
\hline \multirow[t]{2}{*}{ Diseases } & Yes & 369 & $16.93 \pm 4.33$ & \multirow{2}{*}{16.385} & \multirow{2}{*}{0.000} \\
\hline & No & 207 & $13.38 \pm 3.56$ & & \\
\hline \multirow[t]{3}{*}{ Sleep quality } & Good & 206 & $13.76 \pm 2.53$ & \multirow{3}{*}{12.568} & \multirow{3}{*}{0.000} \\
\hline & Not bad & 214 & $15.23 \pm 2.87$ & & \\
\hline & Poor & 156 & $16.23 \pm 3.13$ & & \\
\hline \multirow[t]{2}{*}{ Osteoporosis } & Yes & 315 & $15.78 \pm 4.22$ & & \\
\hline & No & 261 & $13.65 \pm 3.16$ & 6.918 & 0.000 \\
\hline Regular exercise & Yes & 335 & $13.23 \pm 2.09$ & & \\
\hline & No & 241 & $15.34 \pm 3.61$ & 8.145 & 0.000 \\
\hline Subjective well-being & Yes & 415 & $12.54 \pm 2.19$ & & \\
\hline & No & 161 & $15.32 \pm 2.77$ & 11.424 & 0.000 \\
\hline Sense of loneliness & Yes & 228 & $15.23 \pm 3.21$ & & \\
\hline & No & 348 & $12.15 \pm 2.06$ & 12.857 & 0.000 \\
\hline
\end{tabular}

Note: Regular exercise: at least 1 hour per day, 4 times per week; K10: Kessler Psychological Distress Scale.

Table 2. Multivariate Logistic Regression analysis of risk factors of mental status of older women.

\begin{tabular}{ccccccc}
\hline Index & $\boldsymbol{\beta}$ & S.E & Wald $\boldsymbol{\chi}^{\mathbf{2}}$ & $\mathbf{P}$ & OR & 95\% CI \\
\hline Education level & 0.617 & 0.245 & 3.447 & 0.004 & 5.325 & $4.927-7.316$ \\
Living condition & 0.458 & 0.316 & 5.016 & 0.005 & 0.027 & $3.115-9.641$ \\
Salary & 0.632 & 0.216 & 9.241 & 0.00 & 12.123 & $11.334-32.396$ \\
Ability of daily living & 0.431 & 0.272 & 6.732 & 0.000 & 9.626 & $7.834-17.483$ \\
Filial piety & 0.427 & 0.124 & 11.675 & 0.000 & 1.615 & $1.176-3.663$ \\
Diseases & 0.480 & 0.107 & 20.466 & 0.000 & 11.678 & $9.4727-19.365$ \\
Regular exercise & 0.412 & 0.213 & 6.847 & 0.000 & 9.623 & $7.811-16.473$ \\
Sleep quality & 0.581 & 0.352 & 6.718 & 0.000 & 2.463 & $1.687-3.109$ \\
Subjective well-being & 0.898 & 0.109 & 7.376 & 0.000 & 8.934 & $6.292-15.356$ \\
Loneliness & 0.452 & 0.217 & 5.915 & 0.013 & 6.782 & $5.327-10.629$ \\
Osteoporosis & 0.762 & 0.263 & 4.375 & & &
\end{tabular}

Note: OR, odds ratio; CI, confidence interval.

Table 3. Quantification and assignment of possible risk factors for OP.

\begin{tabular}{cccc}
\hline Index & \multicolumn{2}{c}{ Quantification and assignment } \\
\cline { 2 - 4 } & High school or above & Junior high school or below & Literate \\
Education level & Other & Living alone & 4 \\
Living condition & $>3,000$ & $2,000-3,000$ & $1,000-2,000$ \\
Salary (RMB) & No problem & Having some problems & Unable to participant in daily \\
Ability of daily living & Satisfied & Not satisfied & activities \\
Filial piety & No & No & Not bad \\
Diseases (Yes or no) & Yes & No & Poor \\
Regular exercise (Yes or no) & Good & Yes & Yes \\
Sleep quality & No & No &
\end{tabular}

Note: OP: osteoporosis. 


\subsection{The prevalence of $O P$ in older women with different characteristics}

The prevalence of OP was varied by age, menopausal years, age at menarche, BMI, times of pregnancy and delivery, exercise and mental status (all $p<0.05$ ) (Table 4, Figure 1 and Figure 2).

\subsection{Multivariate logistic regression analysis of risk factors of $O P$}

Multivariate logistic regression analysis showed that poor mental health, increasing age, age at menarche $<16$ years, long menopausal years and more delivery times were the risk factors for OP in older women. Regular exercise and high BMI were the protective factors for reduced OP risks (all $p<0.05$, Table 5). The assignment of variables was shown in Table 6.

\subsection{BMD and prevalence of $O P$ in older women with different K10 scores}

BMD value was $0.320(0.254,0.437)$. T value was -2.600 $(-3.357,-1.422)$. A total of 315 patients with OP were detected (54.69\%). Among them, 175 subjects $(30.38 \%)$ were low in bone mass and $86(14.93 \%)$ were normal in bone mass. With

Table 4. Comparison of OP in older women with different characteristics (n, \%).

\begin{tabular}{|c|c|c|c|c|c|}
\hline Index & Cases & $\begin{array}{l}\text { Women } \\
\text { with OP }\end{array}$ & $\begin{array}{l}\text { Prevalence } \\
\text { of OP }\end{array}$ & $\chi^{2}$ & $\mathbf{P}$ \\
\hline $\begin{array}{c}\text { Age at Menarche } \\
\text { (years) }\end{array}$ & & & & 11.383 & 0.000 \\
\hline$<16$ & 466 & 239 & 51.29 & & \\
\hline$\geq 16$ & 110 & 76 & 69.09 & & \\
\hline BMI $\left(\mathbf{k g} / \mathbf{m}^{2}\right)$ & & & & 28.839 & 0.000 \\
\hline$<18.5$ & 156 & 112 & 71.79 & & \\
\hline $18.5-24$ & 218 & 115 & 52.75 & & \\
\hline$\geq 24$ & 202 & 88 & 43.56 & & \\
\hline Delivery times & & & & 20.993 & 0.000 \\
\hline 1 & 118 & 50 & 42.37 & & \\
\hline 2 & 185 & 89 & 48.11 & & \\
\hline$\geq 3$ & 273 & 176 & 64.47 & & \\
\hline Pregnancy times & & & & 12.106 & 0.002 \\
\hline 1 & 83 & 35 & 42.17 & & \\
\hline 2 & 203 & 102 & 50.25 & & \\
\hline$\geq 3$ & 290 & 178 & 61.38 & & \\
\hline Regular exercise & & & & 87.737 & 0.000 \\
\hline Yes & 335 & 128 & 38.21 & & \\
\hline No & 241 & 187 & 77.59 & & \\
\hline Mental status & & & & 23.274 & 0.000 \\
\hline Good & 352 & 169 & 48.01 & & \\
\hline Not bad & 158 & 94 & 59.49 & & \\
\hline $\begin{array}{l}\text { Relatively poor or } \\
\text { poor }\end{array}$ & 66 & 52 & 78.79 & & \\
\hline
\end{tabular}

Note: OP: osteoporosis; BMI: body mass index. the increase of K10 score, the BMD value showed a decreasing trend and the prevalence of OP showed an increasing trend $\left(\chi^{2}=48.238, p<0.001\right)($ Table 7$)$.

\subsection{Correlation between mental health score and BMD in older women}

PCC analysis showed that BMD values of older women were significantly negatively correlated with K10 score ( $\mathrm{r}=-0.932$, $p<0.01$ ) (Figure 3).

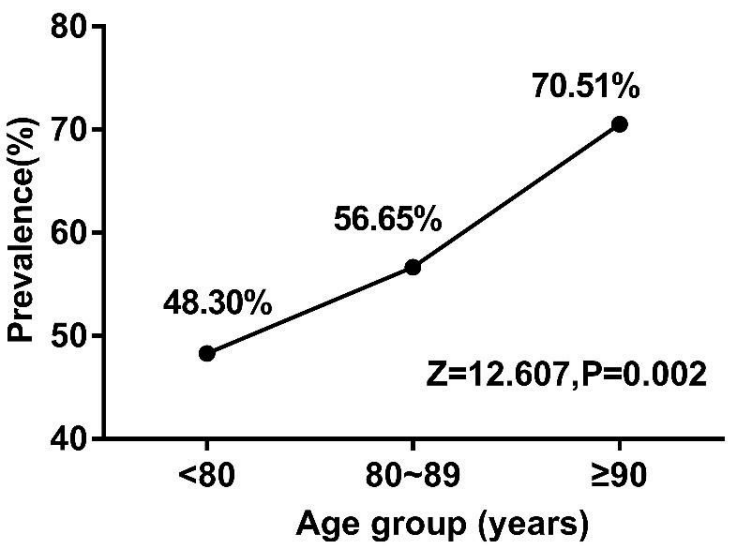

Figure 1. Comparison of prevalence of OP among older women of different ages.

There were 265 people younger than 80 years old, 128 patients having OP; 233 people were from 80 to 89 years old, 132 patients having OP; 78 people were older than 90 years old, 55 patients having OP. OP: osteoporosis.

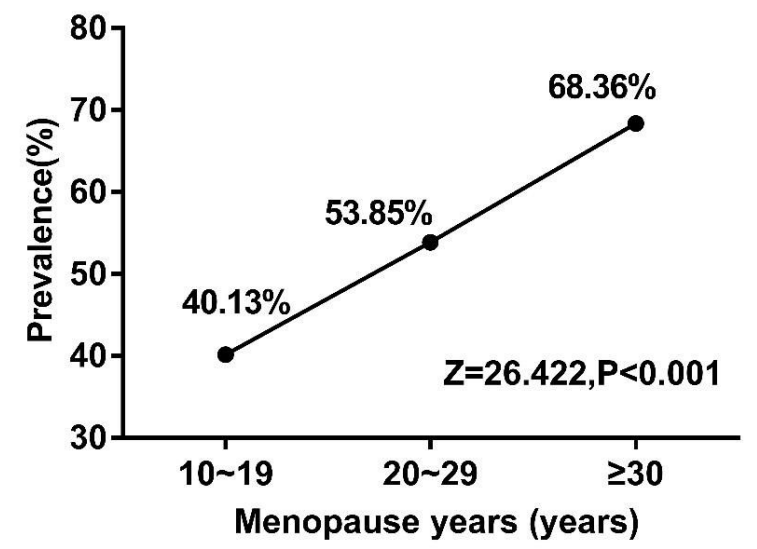

Figure 2. Comparison of prevalence of OP among older women with different menopause years.

There are 152 people who have been menopausal for 10 to 19 years, with 61 patients having OP; 247 people have been menopausal for 20 to 29 years, with 133 patients having OP; 177 have been menopausal for more than 30 years, with 121 patients having OP. OP: osteoporosis. 
Table 5. Multivariate logistic regression analysis of OP risk factors.

\begin{tabular}{ccccccc}
\hline Index & $\boldsymbol{\beta}$ & S.E & Wald $\chi^{2}$ & P & OR & 95\% CI \\
\hline $\begin{array}{c}\text { Age (years) } \\
\text { Duration of menopause }\end{array}$ & 0.616 & 0.307 & 3.841 & 0.004 & 1.853 & $2.783-6.325$ \\
$\quad$ (years) & 0.787 & 0.229 & 12.393 & 0.000 & 0.193 & $2.011-7.342$ \\
Age at Menarche (years) & 1.023 & 0.226 & 19.633 & 0.00 & 2.327 & $1.128-6.630$ \\
BMI & -0.665 & 0.272 & 8.312 & 0.578 & $0.353-0.855$ \\
Delivery times & 0.376 & 0.127 & 9.653 & 0.002 & 1.445 & $1.227-6.619$ \\
Regular exercise & -0.734 & 0.261 & 7.878 & 0.004 & 0.488 & $0.338-0.714$ \\
Mental status & 0.487 & 0.188 & 6.754 & 0.04 & 1.622 & $1.129-3.256$ \\
\hline
\end{tabular}

Note: OP: osteoporosis; BMI: body mass index; OR: odds ratio; CI: confidence interval.

Table 6. Quantification and assignment of possible risk factors for OP.

\begin{tabular}{|c|c|c|c|}
\hline \multirow{2}{*}{ Index } & \multicolumn{3}{|c|}{ Quantification and assignment } \\
\hline & 1 & 2 & 3 \\
\hline Age (years) & $<80$ & $80-89$ & $>90$ \\
\hline Duration of menopause (years) & $10-19$ & $20-29$ & $\geq 30$ \\
\hline Age at Menarche (years) & $\geq 16$ & $<16$ & \\
\hline BMI & $<18.5$ & $18.5-24$ & $\geq 24$ \\
\hline Delivery times & 1 & 2 & $\geq 3$ \\
\hline Pregnancy times & 1 & 2 & $\geq 3$ \\
\hline Regular exercises (Yes or no) & Yes & No & \\
\hline Mental status & Good & Fair & Relatively poor or poor \\
\hline
\end{tabular}

Note: OP: osteoporosis; BMI: body mass index.

Table 7. BMD level and OP prevalence in s older women with different $\mathrm{K} 10$ score $\left(\mathrm{P}_{50}\left(\mathrm{P}_{25} ; \mathrm{P}_{75}\right)\right)$.

\begin{tabular}{|c|c|c|c|c|c|}
\hline K10 score & $\mathbf{n}$ & BMD value $\left(\mathrm{G} / \mathrm{cm}^{2}\right)$ & T value & Women with OP & Prevalence of OP (\%) \\
\hline $10-15$ & 352 & $0.347(0.283 ; 0.441)$ & $-2.200(-2.632,-1.145)$ & 169 & 48.01 \\
\hline $16-21$ & 158 & $0.312(0.258 ; 0.415)$ & $-2.870(-3.526,-1.574)$ & 94 & 59.49 \\
\hline $22-50$ & 66 & $0.269(0.204 ; 0.344)$ & $-3.400(-3.883,-2.652)$ & 52 & 78.79 \\
\hline Total & 576 & $0.320(0.254,0.437)$ & $-2.600(-3.357,-1.422)$ & 315 & 54.69 \\
\hline
\end{tabular}

Note: BMD: body mass density; OP: osteoporosis; K10: Kessler Psychological Distress Scale.

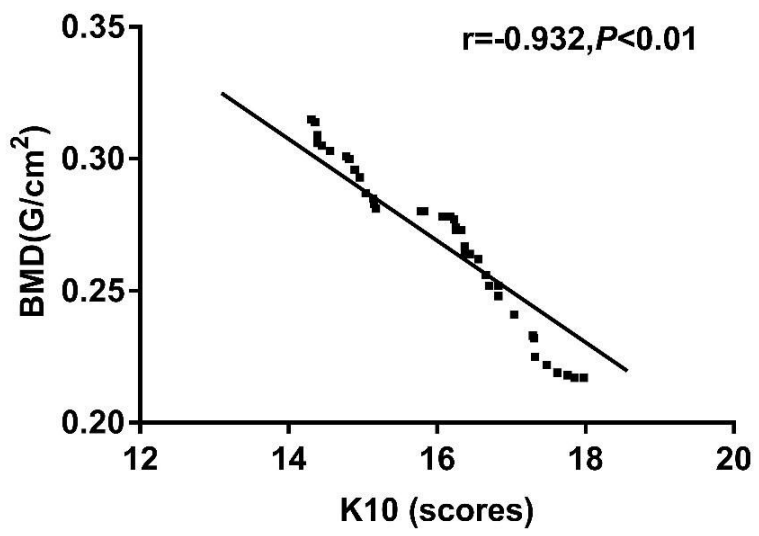

Figure 3. Correlation analysis of K10 score and BMD in older women. K10: Kessler Psychological Distress Scale; BMD: Bone mineral density.

\section{Discussion}

In our study, we find that living alone, self-reported loneliness, and lower salary are the risk factors for poor mental health status among older women. Our findings of the relevance of living alone coincides with the statistics from Beijing Geriatric Care Hotline on mental issues, which showed that $48 \%$ of older adults with depressive tendencies live alone for a long time and have a deep sense of loneliness (Lee et al., 2017a). Secondly, abundant economic income is the most important material basis to ensure the life of the aged women, which can provide a sense of security for them and reduce the concerns about daily life expenditure and their own health (Lidor et al., 2016). We also find that regardless of the daily living expenses, older women who earn less than 1,000 RMB per month have no excess expenses, even for health care and other life-improving activities. In addition to the daily expenses, the older women whose salary is over 3,000 RMB can also enjoy various social 
activities and cultivate hobbies, without worrying about their postmortem handling.

Low education level, poor ability of daily living and dissatisfaction with filial piety are also the important risk factors of bad mental health of older women. Older women with the higher education level have the better mental health without chronic diseases. Older women with higher education level can enrich their life through many channels, such as paper reading and modern news media, expand their interests and hobbies. They can do better in interpersonal relationships, self-regulation, pressure relief, and controlling negative emotions (Wu et al., 2015). Otherwise, older women with better ability of daily living, higher the degree of filial piety satisfaction and better physical health level have the better mental health. Children are also the main factor affecting the mental health of aged people, especially those who live alone or were widowed. Therefore, both high degree of filial piety from children and good relationship with one's children play important roles in reducing the sense of loneliness and bringing more happiness of the aged (Rabelo \& Neri, 2015).

Poor subjective well-being is another risk of bad mental health of older women. The increased age is usually accompanied by a decline in physical function but an increase in prevalence of diseases, which will inevitably lead to less participation in social activities. In the long run, it is likely to bring negative emotions and mental deterioration. In addition, most aged people are suffering from chronic diseases and multiple comorbidities. The multiple pressures and pain brought by diseases will negatively affect their mental health, coming with other issues such as solitary living, low income and so on, which will further intensify their negative emotions (Karapinar et al., 2017).

Meanwhile, suffering from OP or other diseases, poor sleep quality and irregular exercise are also the risk factors for poor mental health of older women. Elderly women who suffer from $\mathrm{OP}$ will bear an increasing incidence of fracture, leading to long-term pain and loss of physical function and more medical expenses. However, regular exercise can strengthen their body and improve resistance. Exercise could induce more dopamine secretion to help the aged maintain good mentality, expand the scope of social activities, enrich their mental world, and reduce the incidence of chronic diseases(Du et al., 2019). Morga et al. (2015) have reported that physical exercise plays an important role in keeping the physical function of the aged, and it can affect their daily activities, mood and mental health. Ewing et al. (2017) also have reported that poor sleep quality is a common early manifestation of mental disorders. Sleep disruption can affect the perception of physical consciousness, and long-term poor sleep quality can also bring negative emotions, which are closely related to mental diseases It also provides scientific evidence that sleep quality and physical exercise can affect the mental health of the aged, which is consistent with the results of this study.

Many elders in China have poor understandings of mental health and mental disorders. For them, accepting formal mental health counseling is equivalent to admitting that they are "psychopaths." Therefore, solving the mental problems of the elders can not only give them individual mental health counseling, but also provide them with different solutions according to different mental problems and corresponding causes. It is also the purpose of our epidemiological research and investigation.

$\mathrm{OP}$ is a systemic metabolic bone disease, featured by low bone mass, disintegration and degradation of bone micro-structure, which results in fragile bone and even fracture. As a multifactorial disease, it is closely related to genes, mental status, living habits and diet. Therefore, its risk assessment and analysis of influencing factors are extremely necessary (Zhu et al., 2018a). Clinically, DEXA can usually predict fracture and the evaluation and diagnosis of OP based on the determination of BMD (Kow et al., 2019). It's rather difficult for doctors in developing countries to get DEXA, and quantitative ultrasound (QUS) equipment has just become a good substitute. Both of them can be used to measure BMD based on the different condition of medical units. Some researchers have confirmed that the bone health index generated by QUS is significantly associated with bone density and fracture risk (Fontes-Pereira et al., 2018).

We have found that poor mental status, increasing age, age at menarche $<16$ years, long menopausal years and more delivery times are all risk factors for increasing OP risk in older women. On the one hand, poor mental health can lead to cognitive decline, loss of interest, increased risk of depression, less exercise, more negative effects such as irregular diet, and insufficient sleep. All of these variables can cause the decline of body function and eventually increase the risk of OP. On the other hand, age is currently one of the most recognized risk factors for OP. After 40 years of age, bone mass begins to decline gradually. At 80 years of age, bone mass is lost to about half of the bone mass peak of human body (Ganguly et al., 2017). Cui et al. (2016) have pointed out that with increasing age, the difference of bone density distribution in older women is greater than that in men, and the peak period of bone loss in women and men is 51-55 years old and 61-65 years old, respectively . Generally, women are in a slight state of bone loss in the premenopausal period, while after menopause, the rate of bone loss is significantly increasing due to estrogen deficiency. This is one of the reasons why the incidence of OP is greater in women than in men, and the incidence of OP in women over 50 years will become higher and higher (Chin et al., 2016).

Young age at menarche (less than 16 years old) and more delivery times may also affect OP of older women. Zhang et al. (2018) have reported that age at menarche in women is significantly correlated with the occurrence of OP and plays an important role in the pathophysiological development of bone-related diseases such as decrease of bone mass, OP and fracture. The initiation of menarche indicates the women's estrogen level is close to that of an adult. The earlier the age at menarche is, the earlier the peak of bone mass is. In addition, during pregnancy, the estrogen level rises significantly and the demand for calcium increases. If the intake of calcium and vitamin $\mathrm{D}$ cannot meet the needs of the mother and fetus, which easily leads to the decrease of bone mass of the mother and increases the risk of OP. Moreover, the risk can be much higher with more delivery times (Zhang et al., 2017).

Some studies have confirmed that BMD is positively correlated with body weight, BMI and height, and negatively correlats with age, menarche time and postmenopausal years 
(Bratke et al., 2017). BMI is a reference value reflecting the comprehensive quality of the human body. People with large body weight often have high level of BMD so as to support the human body needs. Meanwhile, adipose tissue can increase the estrogen level in blood circulation, promote the increase and aromatization of androgen, and reduce osteoclast activity and mineral absorption of bone by combining with the estrogen receptor on the membrane of osteocytes (Török-Oance \& Bala, 2017). However, high BMI is also disadvantageous. The women's adipose tissue is usually accumulated in the abdomen, leading to a large waist circumference, and a high percentage of body fat will increase the risk of OP. Hence, women should strengthen their bone mass through exercises (Horowitz \& Tommasini, 2018). Lee et al. (2017b) have claimed that regular whole body vibration exercise could delay the progress of BMD loss of aged people in Korean nursing homes and regular exercise and adequate calcium intake could effectively prevent fractures. We also show that regular exercise and high BMI are protective factors to reduce the risk of OP in older women, which is consistent with the above-mentioned studies.

In this study, we find that in older women, OP is related to worse mental health status. Regular exercise could help older women maintain a good mental state and reduce their risk of OP. Furthermore, for the disease without obvious symptoms in the initial stage and highly prevalent in older women, its prevention is far greater than the treatment. Thus, it is necessary for older women to keep good living habits, do exercises, and receive regular BMD testing and screening.

However, There are also some limitations. For example, the sample size is limited since the subjects of this investigation are all older women in urban areas of China. In the future, it is necessary to expand the sample size, including eligible subjects in rural areas. The influence of residential environment and regional differences on the mental state and health of older women in their later years is also needed.

In conclusion, the mental health status and bone health of older women are related to a variety of factors. Specifically, women with poor mental health have a higher risk of OP. Regular exercise could help the older women keep good mental health and decrease the risk of OP. Comprehensive means of prevention and control for these specific factors can be considered clinically, so as to improve the mental health status, reduce their incidence of $\mathrm{OP}$, and promote their quality of life in their later years.

\section{References}

Bratke, H., Bruserud, I. S., Brannsether, B., Aßmus, J., Bjerknes, R., Roelants, M., \& Júlíusson, P. B. (2017). Timing of menarche in Norwegian girls: associations with body mass index, waist circumference and skinfold thickness. BMC Pediatrics, 17(1), 138. http://dx.doi.org/10.1186/s12887-017-0893-x. PMid:28587648.

Chin, K. Y., Kamaruddin, A. A., Low, N. Y., \& Ima-Nirwana, S. (2016). Effects of age, sex, and ethnicity on bone health status of the elderly in Kuala Lumpur, Malaysia. Clinical Interventions in Aging, 11, 767-773. http://dx.doi.org/10.2147/CIA.S108772. PMid:27358558.

Cui, R., Zhou, L., Li, Z., Li, Q., Qi, Z., \& Zhang, J. (2016). Assessment risk of osteoporosis in Chinese people: relationship among body mass index, serum lipid profiles, blood glucose, and bone mineral density. Clinical Interventions in Aging, 11, 887-895. http://dx.doi. org/10.2147/CIA.S103845. PMid:27445467.

Darin-Mattsson, A., Andel, R., Celeste, R. K., \& Kåreholt, I. (2018). Linking financial hardship throughout the life-course with psychological distress in old age: Sensitive period, accumulation of risks, and chain of risks hypotheses. Social Science \& Medicine, 201, 111-119. http://dx.doi.org/10.1016/j.socscimed.2018.02.012. PMid:29471180.

Du, C. Y., Li, H. Y., Qu, L. J., Li, Y., \& Bao, X. (2019). Personalized nursing care improves psychological health, quality of life, and postoperative recovery of patients in the general surgery department. International Journal of Clinical and Experimental Medicine, 12(7), 9090-9096. Retrieved from http://ijcem.com/V12_No7.html

Ewing, D. L., Manassei, M., Gould van Praag, C., Philippides, A. O., Critchley, H. D., \& Garfinkel, S. N. (2017). Sleep and the heart: Interoceptive differences linked to poor experiential sleep quality in anxiety and depression. Biological Psychology, 127, 163-172. http://dx.doi.org/10.1016/j.biopsycho.2017.05.011. PMid:28554855.

Fontes-Pereira, A., Rosa, P., Barboza, T., Matusin, D., Freire, A. S., Braz, B. F., Machado, C. B., von Krüger, M. A., Souza, S. A. L., Santelli, R. E., \& Pereira, W. C. A. (2018). Monitoring bone changes due to calcium, magnesium, and phosphorus loss in rat femurs using Quantitative Ultrasound. Scientific Reports, 8(1), 11963. http://dx.doi. org/10.1038/s41598-018-30327-7. PMid:30097589.

Ganguly, P., El-Jawhari, J. J., Giannoudis, P. V., Burska, A. N., Ponchel, F., \& Jones, E. A. (2017). Age-related Changes in Bone Marrow Mesenchymal Stromal Cells: A Potential Impact on Osteoporosis and Osteoarthritis Development. Cell Transplantation, 26(9), 1520 1529. http://dx.doi.org/10.1177/0963689717721201. PMid:29113463.

Gu, F., Jiang, J., Wang, S., Feng, T., Zhou, Y., Ma, Y., \& Shen, S. J. (2019). An experimental research into the potential therapeutic effects of Anti-Osteoporosis Decoction and Yougui Pill on ovariectomyinduced osteoporosis. American Journal of Translational Research, 11(9), 6032-6039. Retrieved from https://www.ncbi.nlm.nih.gov/ pmc/articles/PMC6789260/. PMid:31632571.

Horowitz, M. C., \& Tommasini, S. M. (2018). Fat and Bone: PGC-1a Regulates Mesenchymal Cell Fate during Aging and Osteoporosis. Cell Stem Cell, 23(2), 151-153. http://dx.doi.org/10.1016/j. stem.2018.07.010. PMid:30075123.

Karapinar, M., Firat, T., \& Kirdi, N. (2017). THU0759-HPR Does physiotherapy and rehabilitation program improve mobility and daily living activities in elderly inpatient with osteoporosis? Annals of the Rheumatic Diseases, 76, 1489-1490. http://dx.doi.org/10.1136/ annrheumdis-2017-eular.3884.

Kingstone, T., Burroughs, H., Bartlam, B., Ray, M., Proctor, J., Shepherd, T., Bullock, P., \& Chew-Graham, C. A. (2017). Developing a community-based psycho-social intervention with older people and third sector workers for anxiety and depression: a qualitative study. BMC Family Practice, 18(1), 77. http://dx.doi.org/10.1186/ s12875-017-0648-7. PMid:28701184.

Kow, M., Akam, E., Singh, P., Singh, M., Cox, N., Bhatti, J. S., Tuck, S. P., Francis, R. M., Datta, H., \& Mastana, S. (2019). Vitamin D receptor (VDR) gene polymorphism and osteoporosis risk in White British men. Annals of Human Biology, 46(5), 430-433. http://dx.doi.org/ 10.1080/03014460.2019.1659851. PMid:31448632.

Lee, J. H., Kim, J. J., Kim, J. E., Yoon, S. Y., Kim, J. W., \& Choi, T. Y. (2017a). Quality of life and related factors in elderly people who live alone. European Neuropsychopharmacology, 27, S1123-S1124. http://dx.doi.org/10.1016/S0924-977X(17)31946-6.

Lee, S. M., Kim, S., \& Lim, C. G. (2017b). The effects of milk intake and whole-body vibration exercise on bone mineral density in elderly 
women in nursing homes. Journal of Physical Therapy Science, 29(7), 1125-1128. http://dx.doi.org/10.1589/jpts.29.1125. PMid:28744030.

Lidor, A. O., Molena, D., Stem, M., Blackford, A., \& Pawlik, T. M. (2016). Socioeconomic Disparities Lead to Underutilization of Treatment for Gastric Cancer among the Elderly in the United States. Journal of the American College of Surgeons, 223(4), e36-e36. http://dx.doi. org/10.1016/j.jamcollsurg.2016.08.095.

Link, T. M., \& Kazakia, G. (2020). Update on Imaging-Based Measurement of Bone Mineral Density and Quality. Current Rheumatology Reports, 22(5), 13. http://dx.doi.org/10.1007/s11926-020-00892-w. PMid:32270332.

Morga, P., Traczyk, J., Wittenbeck, K., \& Zygmont, A. (2015). Review of research on the impact of physical activity on mental state of the elderly. Physiotherapy, 23(2), 42-53. http://dx.doi.org/10.1515/ physio-2015-0008.

Rabelo, D. F., \& Neri, A. L. (2015). Tipos de configuração familiar e condições de saúde física e psicológica em idosos. Cadernos de Saude Publica, 31(4), 874-884. http://dx.doi.org/10.1590/0102311X00087514. PMid:25945995.

Spångéus, A., Åkesson, K., Ljunggren, Ö., Banefelt, J., Karlsson, L., Ortsäter, G., Libanati, C., Toth, E., \& Ström, O. (2017). OP0050The treatment gap after fracture in osteoporosis patients in sweden. Annals of the Rheumatic Diseases, 76, 72. http://dx.doi.org/10.1136/ annrheumdis-2017-eular.3397.

Török-Oance, R., \& Bala', M. (2017). Body weight, BMI, and stature have a protective effect on bone mineral density in women with postmenopausal vertebral osteoporosis, whereas greater age at menarche and years after menopause have a negative effect. Asian Biomedicine, 9(1), 81-86. http://dx.doi.org/10.5372/1905-7415.0901.372.
Uddin, M. N., Islam, F. M. A., \& Al Mahmud, A. (2018). Psychometric evaluation of an interview-administered version of the Kessler 10-item questionnaire (K10) for measuring psychological distress in rural Bangladesh. BMJ Open, 8(6), e022967. http://dx.doi.org/10.1136/ bmjopen-2018-022967. PMid:29961041.

Wu, J., Xiao, J., Li, T., Li, X., Sun, H., Chow, E. P., Lu, Y., Tian, T., Li, X., Wang, Q., Zhuang, X., \& Zhang, L. (2015). A cross-sectional survey on the health status and the health-related quality of life of the elderly after flood disaster in Bazhong city, Sichuan, China. BMC Public Health, 15(1), 163. http://dx.doi.org/10.1186/s12889015-1402-5. PMid:25884807.

Zhang, M., Chen, P., Li, B., Du, J., Pan, T., \& Chen, J. (2017). Approach to the patient with pregnancy and lactation-associated osteoporosis: A case report and a review of the literature. Medicine, 96(46), e8671. http://dx.doi.org/10.1097/MD.0000000000008671. PMid:29145296.

Zhang, Q., Greenbaum, J., Zhang, W. D., Sun, C. Q., \& Deng, H. W. (2018). Age at menarche and osteoporosis: A Mendelian randomization study. Bone, 117, 91-97. http://dx.doi.org/10.1016/j.bone.2018.09.015. PMid:30240960.

Zhu, H., Jiang, J., Wang, Q., Zong, J., Zhang, L., Ma, T., Xu, Y., \& Zhang, L. (2018a). Associations between ER $\alpha / \beta$ gene polymorphisms and osteoporosis susceptibility and bone mineral density in postmenopausal women: a systematic review and meta-analysis. BMC Endocrine Disorders, 18(1), 11. http://dx.doi.org/10.1186/s12902-018-0230-x. PMid:29458346.

Zhu, Q., Wang, X. B., Yao, Y., Ning, C. X., Chen, X. P., Luan, F. X., \& Zhao, Y. L. (2018b). Association between anthropometric measures and cardiovascular disease (CVD) risk factors in Hainan centenarians: investigation based on the Centenarian's health study. BMC Cardiovascular Disorders, 18(1), 73. http://dx.doi.org/10.1186/ s12872-018-0810-8. PMid:29716519. 